\section{Did capitation payment reform make a difference in Chinese rural primary health care?}

\author{
Jing Sun, ${ }^{1}$ Jun Kang, ${ }^{2}$ Qian Qu, ${ }^{3}$ \\ Weibin Zhang, ${ }^{3}$ Yongqian Tan, ${ }^{4}$ \\ Wenxian Xiang ${ }^{4}$ \\ ${ }^{1}$ National Institute of Hospital \\ Administration, National Health and \\ Family Planning Commission, Beijing; \\ ${ }^{2}$ Chongqing Medical University, \\ Chongqing; ${ }^{3}$ Chongqing Health Bureau, \\ Chongqing; ${ }^{4}$ Qianjiang Health Bureau, \\ Qianjiang, China
}

\section{Abstract}

This paper evaluated the effect of capitation payment reform in New Rural Cooperative Medical Scheme designating primary facilities in Qianjiang 2007-2009. Retrospective administrative claims were analyzed. Intercepts changes of cost per visit in facilities started the reform in different stages and of overall Qianjiang were compared. Referral rate, prescribing indicators, hospitalization rate, income of facility and individuals were compared pre- and post- the reform. Growth rate of cost per visit in health centers was contained in 2008 , kept unchanged in 2009. Cost containment effect on village clinics was observed in each starting stage of reforms, but vanished later on. Except for the fact the proportion of essential medicines used in health centers significantly increased ( $\chi^{2}$ test, $\left.P<0.05\right)$, prescription indicators were not improved significantly in all facilities. After a slight increase in 2007, the hospitalization rate continuously dropped. The monthly income and outpatient revenue continuously increased in 2006-2009. Cost containment objective of the capitation reform was achieved immediately following the reform, but was not sustainable. Provider behaviors were partially improved with limited effects on prescriptions behaviors. The reform brought no financial loss to both the facilities and individuals.

\section{Introduction}

New Rural Cooperative Medical Scheme (NRCMS) has been providing basic health security for rural residents in China since 2003. The longtime constrained medical needs of farmers have been thus greatly alleviated. ${ }^{1}$ Efforts have been made to improve benefit package, which include covering outpatient services in addition to inpatient services, and reducing co-payment of enrollees. There has been an increasing cost containment pressure on the local governments. ${ }^{2}$ Fee for service (FFS) is the key payment method of NRCMS. Intermixed with other complicated factors, FFS has been creating perverse incentives in Chinese health system, driving the preference of expensive medicines and over prescribing, and intensifying the surging medical costs. ${ }^{3,4}$

There has been a consensus in Qianjiang that, the NRCMS should shift its payment to designated facilities from resource exhausted FFS to pre-paid method. The capitation payment reform in Qianjiang expected to remove the perverse incentives for expensive medicines and over prescribing, thereby to rationalize provider behavior, and to contain the surging medical cost. ${ }^{5}$ The reform in Qianjiang targeted NRCMS designated outpatient services of health centers and village clinics, started in July 2007 in 2 village clinics. Another 49 village clinics followed in January 2008. All other village clinics and 4 health centers joint in October 2008. By January 2009, all health centers and village clinics fully implemented the reform. Annual payment limits were calculated for health centers and village clinics respectively. The limits were calculated based on a set of comprehensive indicators, which included number of population covered and density, scale and equipment of facilities, annual number of outpatient visit, total cost per visit, reimbursement ratio, coefficient to adjust the geographic differences, administrative cost, and satisfaction of enrollees. Former reimbursement and inflation factors were considered. In parallel with the capitation payment reform since 2007, maximum expenditure per prescription was set and adjusted for each year, referral and hospitalization criteria were clearly defined and circulated to all NRCMS designated facilities in Qianjiang. ${ }^{5,6}$

A comprehensive performance assessment system was established to conduct quarterly and year-end evaluations on each individual facility. Irregular and spot checks were also organized to examine every aspect of performance, including management (weighted 31\%), quality of care (weighted 63\%), and patients' satisfaction (weighted 6\%). Payment was made monthly with $80 \%$ of the budgeted expenditure and settled with the other $20 \%$ at the year end. The final $20 \%$ payment could be the full or $20 \%$ cut down, based on the results of various assessment results during the year, and was kept within the budget expenditure. There was no compensation to the overruns, and balance could be kept by individual facilities. ${ }^{6}$ This study evaluated whether the capitation payment reform helped in achieving the primary objectives of cost containment, and provider behavior rationalization (reduction of antibiotics, steroids and infusions). The study also assessed if such a payment reform induced higher referral and hospitalization
Correspondence: Jing Sun, National Institute of Hospital Administration, National Health and Family Planning Commission, 38 Xueyuan Road, Haidian District, 100191 Beijing, China.

Tel. +86.10.62026607 - Fax: +86.10.82311837.

E-mail: sunjingx@yahoo.com

Key words: payment, physician's behavior, cost containment.

Acknowledgements: this work was supported by the World Health Organization [11.001.WP01.CHN01,11.5]. We thank the Qianjiang District Health Bureau for its support to the field survey and data collection. We also thank Chongqing Health Bureau for sharing necessary NRCMS data, providing strong support for the implementation of the study, and allowing us to publish relevant data of Qianjiang.

Contributions: JS and JK were the key designers of the study: JK led the data collection and preliminary analysis, JS provided input into the data analysis and interpretation, wrote the first draft of the manuscript, and made critical revisions of the manuscript. $\mathrm{QQ}$ and $\mathrm{WZ}$ coordinated the data collection. YT and WX contributed to the data collection, analysis and interpretation.

Conflict of interests: the authors declare no potential conflict of interests.

Funding: the paper was supported by a World Health Organization grant: 11.001.WP01. CHN01,11.5.

Received for publication: 25 July 2013

Revision received: 15 September 2013.

Accepted for publication: 25 September 2013

This work is licensed under a Creative Commons Attribution 3.0 License (by-nc 3.0).

(C) Copyright J. Sun et al., 2014

Licensee PAGEPress, Italy

Healthcare in Low-resource Settings 2014; 2:1839 doi:10.4081/hls.2014.1839

rates. Considering that the payment reform might affect the interests of primary health workers, the study also explored if it resulted the facilities and health workers to lose income.

\section{Materials and Methods}

To measure the effect of the reforms piloted in 4 phases, we targeted all 2 village clinics which piloted the reform in phase I, and sampled a number of village clinics and health centers from the facilities which piloted the reforms in phase II and III respectively. Considering that only a very limited number (4) of health centers out of the total 30 piloted the reform in advance of others in phase III, we 
targeted 3 of 4 . The sample size of village clinics was determined to have $10 \%$ of 51 village clinics which piloted the reform in phase I and II. 2 village clinics (locates in different towns) who firstly implement the reform in July 2007 were automatically selected. The corresponding 2 health centers were targeted accordingly. The other one township/community health center was randomly selected from the other towns which reformed in phase III. Followed the principle of 2 village clinics under each selected township/community health center, and excluded 2 village clinics automatically included, 4 village clinics were randomly selected from the village clinics which reform in phase II and were under 3 selected health centers. There were a total of 6 village clinics ( 2 reformed in phase I, 4 reformed in phase II) and 3 health centers (reformed in phase III) targeted as sample facilities.

The study assessed the effect of the reform by measuring changes of total cost per visit, quality of care and income of facility and individual. These changes of 3 groups of sample facilities were compared before and after the reform, compared with overall Qianjiang, and with the maximum expenditure per prescription during 2006-2009 (major components of outpatient service cost are for medicines). Prescribing indicators were used to assess the quality of care, included proportion of essential medicines prescribed, and proportion of prescriptions with antibiotics, steroids and infusions. Referral rate helped to assess if patient selection occurred. Hospitalization rate reflected if patients were shifted from outpatient to inpatient care.

Annual average total costs per visit of each group of sample facilities and overall Qianjiang were calculated based on the data directly extracted from Qianjiang NRCMS management database. It was compared before and after the reform during 2006-2009, and compared with overall Qianjiang and the maximum expenditure per prescription. Health centers and village clinics were compared separately. Quality of care and income data was obtained from surveys in sample facilities. Under the support of Qianjiang Health Bureau, sample facilities were required to track prescriptions, and reported income and revenue. Referral and hospitalization rates were regular data collected annually, which were extracted from the Qianjiang NRCMS management database.

\section{Results}

\section{Cost per visit}

\section{Health centers}

In 2007, no health centers started the reform. The annual average total cost per visit of three sample health centers was CNY 16.71, higher than that of overall Qianjiang health centers (CNY 15.4). Both were above the maximum expenditure per prescription (CNY 15).

Reform in health centers started in four centers in October 2008, three months before the end of 2008. The annual average total cost per visit of three sample health centers reached CNY 17.6, and the overall Qianjaing health centers reached CNY 16.85. Both got increased, and were under the maximum expenditure per prescription (CNY 18). The intercept of three sample health centers was smaller than that of overall health centers 2007-2008: $\mathrm{H}^{\text {sample }}{ }_{07-08}(0.89)<\mathrm{H}^{\text {overall }}{ }_{07-08}(1.45)$. Assumed that the contribution of any changes of three sample facilities (brought by the reform started in October 2008) to 30 overall facilities in 2008 could be neglected. Although reform only implemented three months in 2008, it still gained cost containment effect, as its growth rate got smaller.

The other 26 township health centers joint the reform in January 2009. The annual average total cost per visit of three sample health centers (CNY19.73) and overall Qianjaing health centers (CNY19.34) both further increased and faster in 2009, and the latter increased faster than the former. Both went below the maximum expenditure per prescription (CNY 20). The intercepts of three sample and overall health centers 2008-2009 were: $\mathrm{H}^{\text {overall }}{ }_{08-09}=2.45 ; \quad \mathrm{H}^{\text {sample }}{ }_{08-09}=2.13 . \mathrm{H}^{\text {overall }}{ }_{08}$ ${ }_{09}>\mathrm{H}^{\text {sample }}{ }_{08-09}>\mathrm{H}^{\text {overall }_{07-08}}>\quad \mathrm{H}^{\text {sample }_{07-08}}$. This implied that: i) cost containment effect of reform in three sample health centers in 2008 did not continue in 2009 . The increasing rate of three sample health centers in 2009 was faster than that of overall health centers in 2008; ii) no cost containment effect was observed on the $2^{\text {nd }}$ group of health centers which joint the reform in January 2009, its cost increasing speed was faster than the 1st group (who joined the reform in October 2008) in 2009 (Figure 1).

\section{Village clinics}

Cost per visit of sample village clinics in 2006 was not available. Assumed that there was no significant difference between the sample village clinics and the others before the reform, and contribution brought by two sample village clinics to 158 overall village clinics in 2007 could be neglected. The cost per visit of village clinics in 2006 overall Qianjiang village clinics (CNY 11.56) was regarded as the baseline of the sample village clinics, which represented the $1^{\text {st }}$ group village clinics pioneered the reform in July 2007, and the $2^{\text {nd }}$ group joined the reform in January 2008. The annual average total cost per visit of two sample village clinics (CNY 11.29) got a bit lower than that of the overall village clinics (CNY 11.35) in 2007. Both decreased and were above the maximum expenditure per prescription (CNY 10). Larger intercept of two sample village clinics 2006-2007 $\left(\mathrm{H}^{2}{ }_{06-07}=-0.27\right)$ than that of overall village clinics $\left(\mathrm{H}^{\text {overall }}{ }_{06-07}=-0.21\right)$ was observed in the negative part of Y-axis, which implied slight cost containment effect of reform in 2007 on two pioneer village clinics.

In January 2008, another 49 village clinics jointed the reform. Both two (CNY 10.75) and four sample village clinics (CNY 10.97) got decreased annual average total cost per visit, and both were lower than the maximum expenditure per prescription (CNY 12). On the contrary, that of overall village clinics continuously increased to CNY 12.34. This indicated cost containment effect in July 2007 continued, and there was also positive cost containment effect on the $2^{\text {nd }}$ group of village clinics which started the reform in January 2008. The intercepts of two and four sample village clin-

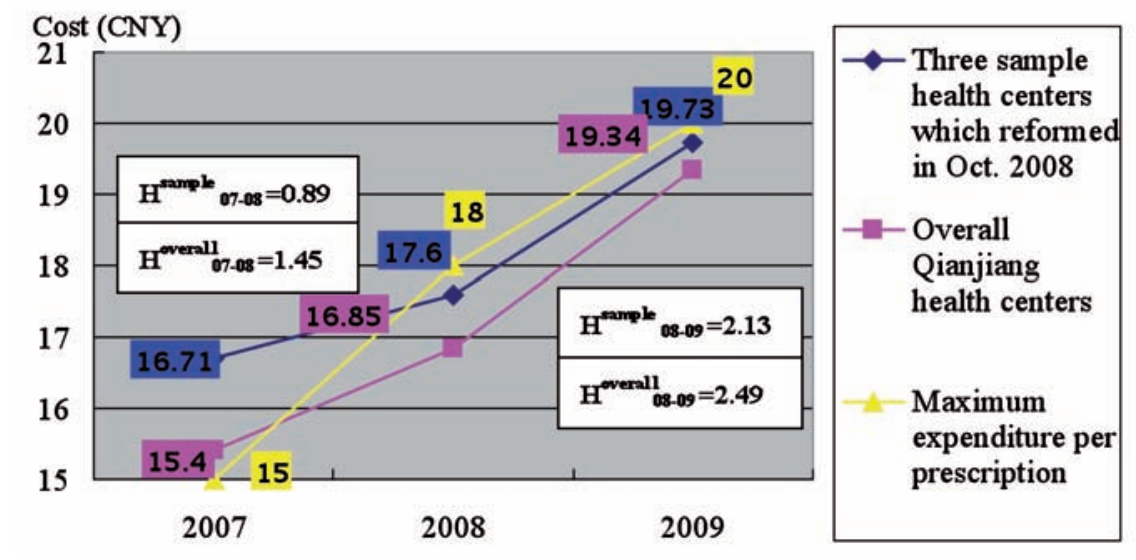

Figure 1. Annual average total cost per visit of health centers 2007-2009. Source: New Rural Cooperative Medical Scheme management database of Qianjiang Health Bureau. 
ics 2007-2008 were: $\mathrm{H}_{07-08}^{2}=-0.54, \mathrm{H}^{4}{ }_{07-08}=-0.16$. $\mathrm{H}^{2}{ }_{07-08}-\mathrm{H}^{2}{ }_{06-07=} \mathrm{H}^{2}{ }_{06-07}<\mathrm{H}^{4}{ }_{07-08}$ indicated that, cost containment effect on $1^{\text {st }}$ group village clinics in 2008 kept same as it was in 2007, and was stronger than that on the $2^{\text {nd }}$ group village clinics who started the reform in January 2008.

In January 2009, all 158 village clinics fully implemented the reform. The annual average total cost per visit of overall village clinics shifted from upward to downward, and decreased to CNY 11.97. On the contrary, that of two and four sample village clinics increased to CNY 11.01 and 11.54. This indicated strong cost containment effect of the reform started in January 2009 on the $3^{\text {rd }}$ group of village clinics (Figure 2).

\section{Quality of care}

During 2007-2009, referral rates of sample health centers ranged between 37.16-36.24\%; proportion of essential medicines used in health centers and village clinics increased from 95 and 98 to $100 \%$; proportion of prescriptions with steroids, antibiotics and infusions continuously went down, from 3.58 to $2.59 \%$ for steroids, from 24.11 to $16.57 \%$ for antibiotics, and from 13.69 to $11.90 \%$ for infusions respectively. Prescription information of village clinics was not analyzed, due to the absence of data. Statistic analysis showed that, these changes between 2007 and 2009 were not significant ( $\chi^{2}$ test, $P>0.05$ ), except that of proportion of essential medicines used in health centers $\left(\chi^{2}\right.$ test, $\left.\mathrm{P}<0.05\right)$ (Table 1$)$.

Prescribing with essential medicines was significantly improved in health centers following the reform, but did not have significant change in village clinics. The other prescription behaviors of health centers did not statistically change as well. These enabled us to conclude that the overall effect of the reform on changing prescription behaviors was not significant. Steroids, antibiotics and infusions prescriptions in village clinics were not assessed due to absence of data. There was no significant change of referral rate following the reform, which implied that reform did not bring unexpected effect, like patient selection.

When there was only two village clinics piloted the reform, and no health centers start- ed the reform in 2007, hospitalization rate of Qianjiang NRCMS enrollees increased from $7.1 \%$ in 2006 to $7.81 \%$ in 2007 . Following an expansion of reform in 2008 in another 49 village clinics in January 2008 and four health centers in October 2008, hospitalization rate of Qianjiang NRCMS enrollees dropped to 6.68\% in 2008. When all village clinics and health centers joint the reform, hospitalization rate of Qianjiang NRCMS enrollees further dropped to
$3.65 \%$ in 2009 (Figure 3).

\section{Income}

The monthly income of health workers in Qianjiang kept growing during 2007-2009, increased from CNY 1683 to 2575 in health centers and CNY 1220 to 1975 in village clinics. The increasing government subsidies to primary care during this period might contribute to the income growth the most. For example,

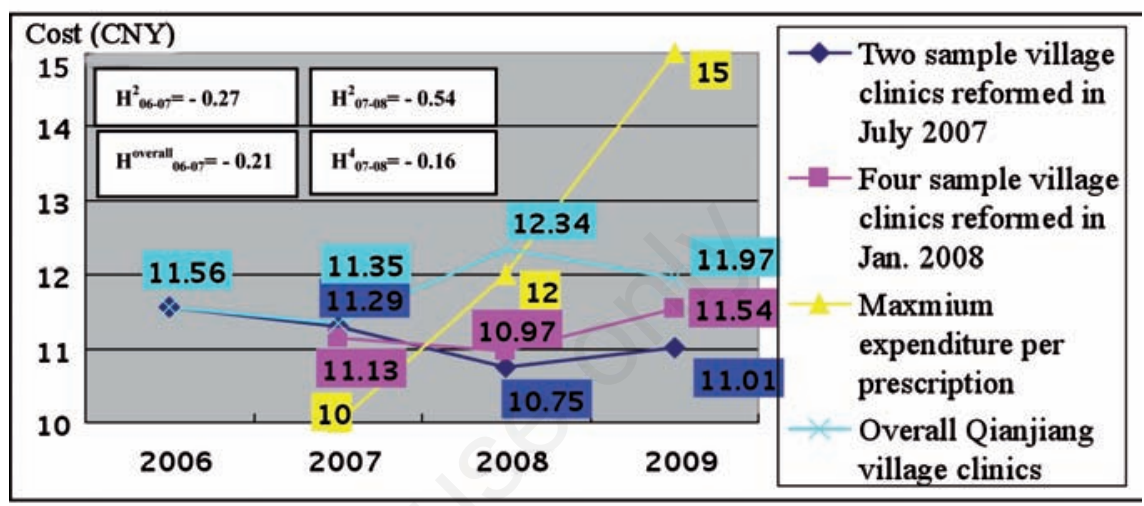

Figure 2. Annual average total cost per visit of village clinics 2006-2009. Source: New Rural Cooperative Medical Scheme management database of Chongqing Health Bureau.

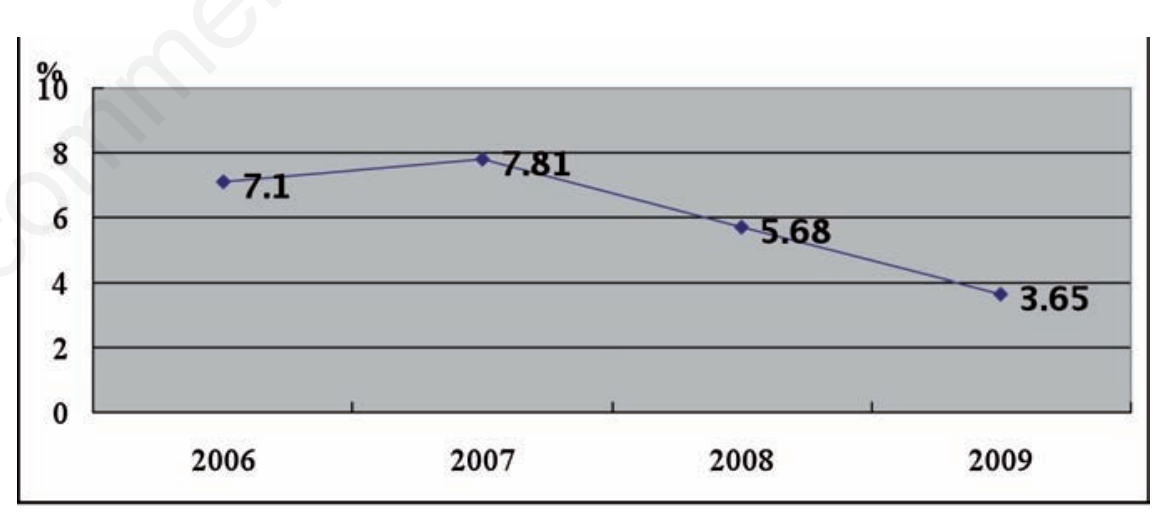

Figure 3. Hospitalization rate of Qianjiang New Rural Cooperative Medical Scheme enrollees 2006-2009. Source: Qianjiang Health Bureau.

Table 1. Quality of care in sample facilities 2007-2009. Source: Qianjiang Health Bureau.

\begin{tabular}{|c|c|c|c|c|c|}
\hline & 2007 & 2008 & 2009 & $X^{2}$ & $\mathbf{P}$ \\
\hline Referral rate in health centers (\%) & 37.16 & 36.45 & 36.24 & 0.018 & 0.8928 \\
\hline $\begin{array}{l}\text { Essential medicines (\%) } \\
\text { Health centers } \\
\text { Village clinics }\end{array}$ & $\begin{array}{l}95 \\
98\end{array}$ & $\begin{array}{l}100 \\
100\end{array}$ & $\begin{array}{l}100 \\
100\end{array}$ & $\begin{array}{l}7.6017 \\
3.0101\end{array}$ & $\begin{array}{l}0.0058 \\
0.0827\end{array}$ \\
\hline Prescriptions with steroids in health centers (\%) & 3.58 & 3.19 & 2.59 & 0.1616 & 0.6877 \\
\hline Prescriptions with antibiotics in health centers (\%) & 24.11 & 19.93 & 16.57 & 1.7573 & 0.185 \\
\hline Prescriptions with infusions in health centers (\%) & 13.69 & 12.92 & 11.90 & 0.1427 & 0.7056 \\
\hline
\end{tabular}


Table 2. Salary, outpatient revenue and surplus of New Rural Cooperative Medical Scheme fund in sample facilities 2007-2009 (CNY). Source: Qianjiang Health Bureau.

$\begin{array}{lcccccccc} & \begin{array}{c}\text { Monthly } \\ \text { income }\end{array} & \begin{array}{c}2007 \\ \text { Outpatient } \\ \text { revenue }\end{array} & \begin{array}{c}\text { NRCMS } \\ \text { outpatient } \\ \text { fund surplus }\end{array} & \begin{array}{c}\text { Monthly Outpatient } \\ \text { income }\end{array} & \begin{array}{c}\text { NRCMS } \\ \text { revenue } \\ \text { outpatient } \\ \text { fund surplus }\end{array} & \begin{array}{c}\text { Monthly } \\ \text { income }\end{array} & \begin{array}{c}2009 \\ \text { revenue }\end{array} \\ \text { Health centers } & 1683 & 896,295 & 38,000 & 1897 & 972,968 & 29,833 & 2575 & 1,248,445 \\ \text { fund surplus }\end{array}$

NRCMS, New Rural Cooperative Medical Scheme.

the secured government subsidy to village doctors increased from CNY 500 per year in 2007 to CNY 1400 per year in 2009. The outpatient revenue of all the sample facilities kept growing during 2007-2009. There were no overruns in all sample facilities in Qianjiang (Table 2).

\section{Discussion}

\section{Cost containment}

Owing to the aging population and the strengthened benefict package of the NRCMS, like most of the other rural areas in China, total cost per visit in Qianjiang has been continuously growing. The capitation payment reform in Qianjiang did not decrease the cost, but contained its growth rate, and achieved the maximum expenditure per prescription target. The reform was implemented in four stages, which did have cost containment effect on both village clinics and health centers during the initial period in each stage (two pioneer village clinics which reformed in July 2007, $2^{\text {nd }}$ group of village clinics which started to reform in January 2008, $3^{\text {rd }}$ group of village clinics which started to reform in October 2008, three pioneer health centers started in October 2008, $2^{\text {nd }}$ group of health centers started in January 2009). Except 2 pioneer village clinics, which continued the cost containment effect in its second period of reform implementation in 2008 , all other facilities were observed with an inconsistent cost containment effect of reform in 2009. Such a phenomenon was caused by a shift of NRCMS management function from Health Bureau to the Insurance Bureau in 2009. Management and supervision were slacked in that year.

\section{Quality of care}

Overall prescription behaviors were observed with no significant changes, except of a significant increase of using essential medicines in health centers. Prescription behaviors are complex and are affected by multiple perverse incentives like pricing system and others, single capitation payment reform approach might not be able to make a complete change of it. Changing prescription behaviors will need more comprehensive interventions with multiple approaches.

Unchanged referral rate implied that, under the capitation payment reform, prescribers did not simply reduce services, or select patients with minor illness to avoid comprehensive treatment. The unexpected effects of capitation payment ${ }^{8,9}$ were successfully averted. Comprehensive performance assessment system valued workload and controlled revisit rate for the same symposium within $72 \mathrm{~h}$. A set of specific and comprehensive indicators with considerable weights to secure the quality of care greatly contributed to this success. Linking the capitation payment with comprehensive performance assessment system secured the quality of care under cost containment pressure.

\section{Hospitalization rate}

A systematic review of hospitalization rate in China ${ }^{10}$ conducted a merger analysis with the $3^{\text {rd }}$ National Health Service Survey (NHSS) data it found that hospitalization rate of rural China was $3.82 \%$ before 2008 . The $3^{\text {rd }}$ and $4^{\text {th }}$ NHSS gave the age-standardized hospitalization rate in rural China in 2003 and 2008, ${ }^{11}$ which ranged between $3-3.7 \%$ for rural areas with high to low annual net income per capita in 2003, and 5.9-7.2\% for 2008. 2008 hospitalization rate was almost twice of that in 2003.

Qianjiang falls into the low income category. Comparing the hospitalization rate of Qianjiang NRCMS enrollees in 2006 (4.06\%) with the systematic review data before 2008 $(3.82 \%)$, we found that they were around the same level. If there were no effective interventions, we assumed that the significant growth of rural hospitalization rate at national level during 2003-2008 should happen in Qianjiang during 2006-2009 as well. The increasing trend during 2006-2007 in Qianjing was in line with this assumption, when the capitation payment reform was yet implemented in most of the facilities in Qianjiang (except two pioneer village clinics). Qianjiang was at the national level in 2007 (4.73\%), it dropped to $2.87 \%$ in 2008 , which was far below the rural national level (3.7\%, low income category). This implied that, expanded reform in all village clinics and four pioneer health centers in Qianjiang between January and October 2008 had a strong effect on reducing hospitalization rate of NRCMS enrollees. The following increasing trend had it reached to $4.57 \%$ in 2009 , which was still below the rural national level (low income category). Rebounded hospitalization rate was also in line with the cost changes in 2009, which was due to the same fact that, NRCMS management function shifted from Health Bureau to the Insurance Bureau in 2009, management and supervision were slacked in that year. To explain a comparatively low hospitalization rate of Qianjiang NRCMS enrollees, we should not forget that, in parallel with the capitation payment reform, Qianjiang developed supporting policies which imposed strict admission standard and strengthened supervision on inpatient services of NRCMS designated facilities in 2007. Hospitalization criteria were clearly defined and circulated to all NRCMS designated facilities. These were important contributors for controlling unnecessary hospitalizations under the outpatient capitation payment reform in Qianjiang.

\section{Income}

The no overruns result and the continuously increased staff salary of health centers and village clinics in Qianjiang showed that, maximum expenditure per prescription, insurance payment budget limit, and relevant supporting policies in inpatient services in Qianjiang secured a steady implementation of the capitation payment reform, and had no negative impact on the operation of the facilities and the income of the health workers.

\section{Conclusions}

Cost containment objective of the capitation reform was achieved but were not sustainable in Qianjiang. Provider behaviors were partially improved but with limited effect on prescriptions behaviors. Careful development of comprehensive performance assessment system 
and supporting policies were crucial to address the unexpected effects of capitation payment, like patient selection and unnecessary hospitalization. The reform brought no financial loss to both the facilities and the individuals.

\section{Limitations}

\section{Availability of data}

In order to relief data collection workload, the study heavily relied on administrative data of Qianjiang Health Bureaus. Data was collected annually as an average, quarterly or monthly data was not available. The assessment was then a rough trend analysis rather than a strict interrupted time series analysis.

\section{Quality of data}

Data were obtained from Qianjiang Health Bureaus, and were reported by individual facilities. Although Chongqing and Qianjiang Health Bureaus organized regular trainings for lower level health bureaus and facilities, helped them in conducting appropriate data collection and reporting, possible quality problems may still exist. We assumed that the reported data is true and correct.

\section{Sampling}

Reform started in two village clinics in July 2007, and expanded to all primary facilities of Qianjiang until January 2009. It was implemented step by step in four stages within one and half year. It was difficult to design a good sampling model for concise measurement and accurate revelation of the changes. Annual average data for Qianjiang covered facilities which reformed in different time period, which was affected by the reforms different groups of facilities. Although the contributors were only a small number of facilities comparing with overall Qianjiang, its contribution was weak and could be neglected, 2007 and 2008 annual average data of overall Qianjiang village clinics was not a perfect controller for two pioneer village clinics and four sample village clinics. This was the same case that, 2008 annual average data of overall Qianjiang health centers was not a perfect controller for four pioneer health centers.

\section{Mixed policy effect}

Although the payment reform was the most important reform in Qianjiang during 20062009 , there were tremendous policy changes under the overall health system reform framework during the same period. Other policy changes might not directly link with the NRCMS payment, but might indirectly contribute to the effects either positively or negatively. The evaluation drew mixed effects of all those policy changes, among which the payment reform contributed the most. Comparison among different groups of facilities which reformed in different stages helped to control confounding policies effects.

\section{Patient care and facility indicator}

Consultation time, dispensing time, patients' satisfaction, patients' perception on medicines use, and availability of key essential medicines are important indicators for comprehensive assessment on quality of care. However, they were not regularly collected and recorded in Qianjiang. This study did not include these patient care and facility indicators, instead of focusing on prescribing indicators and referral rate. The aim was to focus analysis on prescribing behavior changes.

\section{References}

1. Ministry of Health of China. The new rural cooperative medical scheme (NRCMS) in China. Beijing: Ministry of Health ed.; 2008.

2. Zhang L, Liu YG. A case study of rural health policy and management reform in Qianjiang, Chongqing. Beijing: China Financial and Economic Publ.; 2007.

3. Wang YF. Practice and research on the payment reform of medical insurance. China Medicine Bulletin 2004;4:28-30.

4. Gosden T, Forland F, Kristiansen I, et al. Capitation, salary, fee-for-service and mixed systems of payment: effects on the behavior of primary care physicians. Chinese Journal of Evidence-Based Medicine 2008;8:416-7.

5. NRCMS Committee. Announcement to pilot the capitation payment reform in the outpatient of primary facilities. No.11. Qianjiang: Qianjiang Health Bureau ed.; 2007.

6. NRCMS Committee. Announcement to strengthen hospitalization service in NRCMS designated health facilities. No. 2. Qianjiang: Qianjiang Health Bureau ed.; 2007.

7. Wang J. Clinical epidemiology-design, measurement and evaluation of clinical study. Shanghai: Science and technology Publ.; 2009.

8. Yang W, Xuan L, Shen RH, Gu ZL. Policy effect analysis of the capitation payment to the outpatient free medical care program. Chinese Health Economics 1999;18:57-9.

9. Meng QY. Cost containment impact analysis of the payment method of medical insurance. Health Economics Research 2002;9:18-21.

10. Lei HC, Wang J, Liu XL. Study of national hospitalization rate in China second-hand data. A systematic review approach. Chin J Hosp Admin 2008;24:649-52.

11. Ministry of Health of China. An analysis report of National Health Service survey in China, 2008. Beijing: China Medical Union University Publ.; 2008. Available: http://www.moh.gov.cn/cmsresources/moh wsbwstjxxzx/cmsrsdocument/doc9911.pdf 